\title{
Para pensar a cultura
}

Os TERM OS CULTURA E EDUCAÇÃo remetem a um processo, enão a um dado ou a uma realidade acabada: o da humanização. Educação é um conceito quesedifundeesetorna fecundo no século XVIII. Certamenteapareceantes, quer nos antigos, quer, no início dos tempos modernos, deformaful gurante, com Erasmo. Mas sua produtividade propriamente dita data do século XVIII. ${ }^{1}$ Insisto nessa idéia de queo decisivo, no pensamento, équando ele se torna fecundo ou produtivo. O importante não équando umaidéia ou prática nasce, mas quando passa a ter forte efeito multiplicador. Três exemplos bastarão. O primeiro é o da pólvora, no caso, uma técnica e não uma idéia. Sabe-se que desde inícios de nossa era os chineses a utilizavam, mas não para fins belicosos e sim, basicamente, sob a forma de fogos de artifício. É quando essa invenção já antiga é engrenada, pelos ocidentais, na expansão deuma máquina deguerra, queela setorna fecunda, ecom isso modifica o mapa do mundo. Deste exemplo, al iás, evidenciase que ao falar em fecundidade não estou supondo nenhumjuízo devalor. Umsegundo exemplo é o da geometria. Desde os gregos ela é uma ciência reconhecida, e com um campo determinado de validade - no caso, bastante estrito. No século XVII, porém, ela passa a ser uma ferramenta utilíssima para conferir cientificidade a todos os campos do saber. Seu riquíssimo papel consiste, pois, na extensão de sua aplicação a domínios que, antes, Ihe escapavam. Assim a emprega Descartes, quea elogia no $D$ iscurso do método. A ssim permite ela que Hobbes, até então um humanista, que traduzia a H istória da Guerra do Peloponeso de Tucídides para ensinar seus conterrâneos a não se rebelar contra o rei, torne-se um cientista, que não apenas desenvolverá uma física, mas também procurará geometrizar a demonstração em ciênciapolítica. Finalmente, terceiroexemplo, o da ampliação de procedimentos fundamentais da antropologia - penso sobretudo nesse princípio que é o da atribuição de 
significações, pelo agente, a seus atos - a outras áreas da pesquisa, em especial, a históriadasmentalidades: GeorgesDuby, um dos maiores historiadores de nosso tempo, assim reconhecea dívida dosqueestudam as mentalités, entre outros lugares, em seu Guilherme M arechal.

A postura que aqui sustento tem a ver com uma nova ênfase, quesedesloca da produção de um pensamento ou de um bem cultural para essa outra forma de produção que é a recepção, que podemos também chamar de apropriação social. A idéia não é apenas a de produzir uma idéia ou uma prática, mas éa de ver como essa construção humana se difunde. O grande contraste que temos, para ilustrar essa diferença, está nos inícios da modernidade. Costuma-se dizer que a Renascença, com toda a sua riqueza, não soube, porém, gerar uma apropriação social de seus efeitos tão produtiva quanto a quea Reforma propiciou. Daí, inúmeras diferenças entre os modelos, digamos, da Itália e da "Europa do Norte", 2 no que diz respeito aos séculos que se seguiram. Essa distinção éum pouco simplificada, porque, afinal, a Ale manha no século XVII, devido à Guerra dos Trinta Anos, arruinou-se; mas permite entender o deslanche que Holanda e Inglaterra terão, e a longa estagnação italiana. 0 decisivo, então, é saber como ocorre a apropriação social do pensamento.

Estas observações preliminares devem orientar uma discussão sobre o que pode ser a cultura no século por entrar. A ntes de mais nada, lembremos que o conceito de cultura é utilizado hoje em dois sentidos principais. Poderia, aliás, antes de tratar disso comentar a vinculação que tem o termo cultura com o seu congênere que se refere ao cultivo da terra: nos dois casos, contrasta-se o abandonado, o homem ou o terreno inculto, com aquele que recebeu tratos, que pela mão do homem passou do agreste, da waste land, para o fértil, ofecundo, ogerador devida; nos dois casos, pois, a vida resulta do trabalho humano, longe de constituir apenas uma espontaneidade biológica. Poderia, também, pensar na relação que tem a cultura com o culto, eassinal ar comoambosapontamtraços distintivos do sagrado: queel eseja separado, posto à parte, do comum, do cotidiano, do vulgar; que essa distinção corresponda à sua instituição como uma excelência; e que nos doiscasosseenfatizequetal separação resulta da ação humana, quelavra aterra, queestuda o importante, que exal ta o deus. Mas prefiro, noslimites dequeora disponho, pensar outra questão:quesentidoshojesedão, usualmente, ao termo.

São, basicamente, dois, que para simplificar chamarei, no quadro deste artigo, de cultura1 e cultura-2.

O primeiro - emais usual - tomou conta, por exemplo, da linguagem cotidiana e das instituiçõespúblicas. Por ele, cultura, tal como aparecenosnomes desecretarias, pró-reitorias eaté ministérios, bem como nos de cadernos dejornais, poderiaser maisou menosdefinido como uma produção que, antes demaisnada, se distingue por um diferencial em face da utilidade. N ão pertenceàquilo quesefaz para ganhar dinheiro ou para a profissão, mas caracteriza, vistapelo ângulo deseu consumo ou recepção, o tempo delazer. Daí, aliás, para pegar unsnomesa esmo, queseja o "Caderno D ois", o "Caderno B", a "Folha Ilustrada" termos, todos esses, queindicam uma coisa a par do principal, secundáriatalvez, da ordem do adorno ou do enfeite. O mundo, com sua seriedade, ocupa os cadernos que tratam da política nacional ou internacional, da economia, até mesmo da vida cotidiana em nossas cidades. Para o fim, porém (eisso vale até quando o caderno é "dois"), fica o lazer. Tentemos sintetizar essa idéia de cultura: ela é a mais usual, e toma conta tanto das instituições depoder quanto do senso comum veiculado na imprensa; refere-se mais à sensibilidadeeàintuição do queàrazão, mais ao consumo do queà produção, mais ao lazer do queao trabalho, mesmo queisso implique, na compreensão assim definida, uma dificuldade extraordinária de se entender o 
queéo trabal ho próprio do artista, suacriação, de que nada ou quase nada se diz senão mitos, termos vagos, equivocados. Vamos chamá-la neste artigo, para facilitar, de cultura-1.

Finalmente, e aqui talvez esteja sua maior qualidade, esse conceito de cultura confere destaque sobretudo ao que eu chamarei o espaço leigo. Com efeito, em nossa sociedade vivemosem boamedida definidospor nossas profissões. Ora, o termo profissão é de evidentelavra religiosa. Quem tem profissão não é apenas o especialista, o expert da modernidade - é, desde os antigos, aquele que professa determinada fé, determinada pertençaatal ou qual grupo. Um homem sem profissão, assim, éum desterrado, umaespécie deateu dosempregos, um ateu do mundo em que o trabalho, subordinado ao capital, rege os territórios psíquicos.

Masnão serájustamenteesseaté́smo discreto do homem sem profissão o ponto em que ele é mais valioso? Porque o espaço político e social é, essencialmente, um espaço leigo. É nele que nos encontramos, nele que interagimos, com base justamente em nossa nãoprofissão. Não me refiro apenas ao velho princípio das boas maneiras, bem expresso nas artes de conversação dos séculos XVIII e XIX, segundo o qual é de péssimo gosto conversar sobre o trabalho, o emprego, a profissão - o que já define o lugar em que as pessoas entram em contato, socialmente, como um território que exclui a entrega demasiado estrita deféa tal ou qual especialidade. Se há encontro social (e insisto em empregar um termo queporvezestemmáfama, delineando um "amenos", emcontrastecom osencontros íntimos, amorosos ou de amizade, que imprimem a verdade, ou os encontros de trabalho, que exprimem a seriedade), é justamente nesse no man's land em que se define um território de todos a partir, exatamente, da vacuidade que inicialmente possui.

O quepodemospropor, então, pararenovaro conceito decultura, embora partindo mesmo desse esvaziamento a que el e foi submetido, e que faz institucionalmente da Cultura a prima pobredaCiênciaeTecnologia(elasim, emborapobreno contexto geral doorçamento ou da sociedade, a que tem dignidade por falar com seriedadeecomverdade), éapostar precisamente nesse vazio, e lembrar que é nele que se gera - e gere - o que é mais importante na condição humana. Pois esta não é, a princípio ou por princípio, profissionalizada ou religiosa. Ela tem de interessante, navariedademesma demanei ras pelas quais se modaliza, uma certa neutralidade, uma laicidade na qual convém investir. E éa cultura, nesse primeiro sentido, que melhor indica esse caráter plural, eao mesmo tempo vazio, de uma prática - penso sobretudo na recepção cultural - que permite fazer circularem as referências as mais diversas, as proveniências as mais variadas, tendo por positivo enão por negativo o fato demostrar, quem as recebe, quem delas seapropria, uma ligaçãobastantefrouxacomelas, umapertença inexistente ou, quando muito, light. É isso a cultura: antes demaisnada, umafrouxamento doselosquenosprendemanossafédeorigem, a nossa profissão, a nossa lealdade. É isso, bemmaisdoqueas belasartesou osmomentos deexcelência da criatividadehumana. Poiso velho discurso do homem culto, que na sua cultura superior hauria elementos eficazes para firmar seu primado social, já não cabe. Não é mais o caso de repetir frases sobre o patrimônio da humanidade, a que tanto devemos. A eledevemos muito, sem dúvida, mas não tanto para entendêlo como patrimônio - outra idéia de pertença- esim como essa apropriação que afrouxa os elos, que distende os vínculos, que relaxa as identidades. É dessaformaqueocorreaapropriação social dequeantesfalava: demodo a instituir identificações variáveis, passíveis de freqüente mudança.

Um segundo sentido de cultura - que, por simplificação, chamaremos neste artigo de cultura-2 - éaquelequesediz, geralmente, 0 "antropológico". Trata-se, aqui, mais de um 
conceito do que de uma acepção corrente. Poucas instituições - praticamente só as acadêmicas- menosjornaisainda, o utilizam. Contentar-me-ei, tratando dele, em enfatizar a oposição que estabelece com o termo natureza. Um elemento imaginário narrado por Hélène Clastres em seu A terra sem mal ${ }^{3}$ mereceser lembrado. Tratando dosguaranis, ela comenta que devem, para socializar-se, pôr em comumacaça obtida. O caçador, aliás, sequer come o animal que matou: esteétodo paraser distribuído, demodo quea atividade primordial do varão acaba sempre orientada para a socialização. Ora, disto sesegueque, se um homem comenafloresta o animal caçado, ou seja, se o faz longe da aldeia, ou seja, fora da sociedade, ou ainda, se o come sozinho, sem reparti-lo, sem a generosidade que está na raiz da instituição do mundo social, elese estará excluindo não só da relação com o socius mas, também esobretudo, do próprio espaço humano. O egoístaseanimaliza, pior, bestializa-se.

Essa narração é parti cularmenteinteressante porque ela ilustra um aspecto geralmente pouco acentuado na oposição naturezacultura. Nesse par binário, costuma-se ressaltar que a cultura é instituída por um longo processo, que em princípio jamais tem fim, pelo qual o homem se faz a si próprio: a cultura, emelhor dizendo a própria condição humana, têm de próprios serem obra do próprio homem. Nisso residem sua fragilidade, suaefemeridade, talvez suadignidade, mas esta mesma sempre precária. Ora, o que devemos notar é que o processo de constituição deuma identidade humana, trôpega que seja, tem ainda como adicional o fato de que sobre ele constantementepaira a ameaça de ser revertido, de ser desfeito. O homem que não se socializa se bestializa. Quem não secomunicadaformapropriamentehumana, que é algum tipo de dom regido por um esquema de trocas simétricas, há de perder a própria humanidade. Não há, pois, natureza humana, como algo fixo, estático, como uma pertencençacapaz dedefinir-nos. Ser humano é, justamente, não ter natureza: é ser incerto,

\section{é ser cultura.}

A lição dada pelos guaranis de H. Clastres é fundamental, e não é por acaso que, falando em antropologia, preferi, para perturbar as relaçõesentresujeito eobjeto, entreo cientista eseu corpus, começar tratando do queo índio ensina - no caso, a precariedade de ser-se humano - e não do que o civilizado que o estuda pretende provar. Mas, para não corrermos o risco de confundir as ênfases essenciais da antropologia com sua vertente indigenista, passemos ao que constitui a visada eidética dessa disciplina, a que ela deve boa parte de sua relevância e impacto para as demais ciências humanas: para se conhecer o ser humano, deve-se verificar que significaçõesatribuímosnósanossas práticas. Umadescrição secadasmesmaséfrancamente insuficiente. Essa convicção, que a antropol ogia reparte com a fenomenologia, à qual ela certamentedevebastante, ecoma história dasmentalidades, quelhedevemuito, implica a ineficiência dos modelos puramente estruturais de conhecimento do homem (curiosamente, umantropólogo estruturalista como Lévi-Strauss, adepto que foi da formalização matemática, nem por isso deixa de construir, utilizando-a, redes de significações). Essa atribuição de significados é por assim dizer o gesto primordial da humanização, aquele pelo qual o homem se recorta de um mundo supostamente dado, reiterativo, queseria a natureza (a qual, aliás, funciona não poucas vezes como o mito a validar, pelo viés negativo, o que se diz da construção do homem: é preciso haver uma natureza sempre igual a si mesma, regida pelo princípio de identidade, para que a cultura possa destoar desse paradigma e destacar-secomo umcampo não-aristotélico, mais até, anti-aristotélico). Em outras palavras, a construção do homem, ou o homem enquanto construto, somente são possíveis na medida em queem vez de pensarmos sua separação do mundo animal a partir, como Marx, do trabalho, ou, como Arthur Clarkee Stanley Kubrick em 2001, da ferramenta, concentremos esse corte com a natureza na 
produção de significações. O original nessa teoria sobre o queédistintivo no ser humano - ou seja, o queéa cultura - está em conceber - gesto de aparência mais idealista, ou seja, a invenção de significações, como algo extremamente produtivo, articulado às práticas e não a um mundo das idéias.

Propostas estas distinções, que se referem, repito, aosdoisusosmaisconhecidos dotermo mas não os esgotam, nem o esgotam, resta mostrar que dinâmica essas duas acepções estabelecementresi. O primeiro usotemaseu crédito ser o mais corrente, eao mesmo tempo o de maior eficácia junto tanto à opinião pública, ao sensus communis, quanto ao poder ede suas instituições. Já o segundo éo de maior densidade intelectual. Podemos sugerir quea dinâmica entreambosocorrena medida em que a cultura-2 aponta os fins para os quais contribui a cultura-1: o papel, hoje, da cultura enquanto um elenco de informações e formações é servir ao interminável - processo de construção do ser humano.

Isto implicaque, sem seabandonar a idéia de que a cultura (em primeiro sentido) tenha parte com a excelência das obras nela trabalhadas, e com sua ligação a um patrimônio da humanidade, esses dois supostos perdem algo deseu vigor. Continua valendo dealgummodoatópicadaexcelência, jáqueacultura-1sedefinepor umaqualidade de seu fazer, que excede a do usual, a do diaa-dia (daí, o erro das proposições, que se difundiram na década de 1960 e 70, como "disco é cultura" etc.), mas perde ela a centralidadequeaparece, por exemplo, numa expressão como "belas-artes". Quanto à temática do patrimônio, ela continua merecendo atenção, mas a ênfase se desloca decisivamente, desse enraizamento num passado, desse trabalho da memória que a idéiadeumaherançaaponta, paraarecepção, a apropriação social do fazer cultural.

Por isso, simplificando, o destaque passa a ser do futuro, mais que do passado, do modo como a alta qualidade se socializa, mais que das maneiras como ela é preservada.

E é essa mudança de enfoque que permite destacar o modo como se constrói o ser humano, para tanto usando - entre outros elementos, de menor qualidade, de menor sistematicidade, de outros modos deser - da cultura-1 para semontar a cultura-2. Percebese o caráter estratégico dessa mudança de perspectiva. Enquanto se privilegiavam a excelência e o patrimônio, o usuário ou espectador das belas-artespouco tinhaafazer senão utilizá-la de maneira, digamos, pouco artística. O recorteentrea criação ea recepção da cultura-1 era a tal ponto decisivo que obscureciaoqueéotrabalho, tambémcultural (no sentido da cultura-2), e em certa medida até criativo (de cultura-1), que o receptor da arteexecutava. Daí que, perdendo-sedevista o caráter cultural do quefaz o espectador das artes, a caracterização deste se tornava sobretudo social. Explico-me. Não se entendendo em que medida quem consome, usa ou recebebelas-artestambémestáfazendo algoquecompartilhadanaturezadessasobras artísticas, reduzindo-se seu papel ao de uma passiva fruição, só restava pensá-lo a partir de sua posição na sociedade, a qual posição, por sua vez, se compreendia por uma evacuação do quetivessedecultural: passava a assentar numa leitura dos interesses, como aquela que estuda as classes sociais, e não numa dos desejos, como a que trabal ha com identidades lábeis e sempre perturbadas. Sendo uma leitura dos interesses, tornava-se legítimo enecessáriocompreender o consumo das belas-artes com base no uso que dele fizessemosconsumidores, paraassentar suas posições no interior de uma sociedade hierarquizada: era esseuso da cultura-1 o que fundava uma sociedade desigual, cuja desigual dadeé( $r$ )estabelecida. em boa parte, pelo diferenciado acesso aos bens culturais. Não contesto essa leitura, que tem suas qualidades inegáveis. A penas observo que ela elidealgo queéessencial no quepodemos chamar o trabalho da cultura (da cultura-2, sobretudo): o modo como a cultura-1, sem se esgotar em seu uso para delinear hierarquias 
marcadas através da linguagem e do gosto, é alvo deumaapropriação quevai construindo o ser humano. Em outras palavras, há que ouvir a lição da antropologia, e não apenas contrastar os dois sentidos de cultura, mas mostrar que hoje o propriamente enrique cedor no primeiro, emaistradicional, depende amplamente de estar ele iluminado pelo segundo, e mais revolucionário. Em suma, o uso mesmo da teoria da recepção para se compreender as obras de arte, que é um dos grandes aportes da teoria literária nesse fim de século, somente se consolida quando passamos a pensar a cultura-1, para a qual ela foi instituída, sob o enfoque da cultura- 2 .

Convém esclarecer. O domínio de mais e mais linguagens culturais - a literatura, por exemplo - tem valor não apenas por definir uma educação dosgostos, maspor ampliar as possibilidades de construção de uma identidade pessoal. Esta é necessariamente plural. Em nossa sociedade, as possibilidades de felicidadea partir de uma identidade dada e estabelecida se tornam cada vez menores. É tal a complexidade dos investimentos que recebemos, que se torna necessário, para a própria vida psíquica, permitir que ela seja construída, pelo e no interessado, a partir de uma série de identificações elas mesmas diferentes e até contraditórias entre si. Isto, que se torna convicção crescente entre não poucos dos que trabalham a psique, se pode ilustrar por um exemplo da recente história irlandesa.

A República da Irlanda, ao se constituir, fez questão de apostar - contra o domínio britânico que coincidira com a imposição do protestantismo, bem-sucedida nos condados nortistas do Ulster - numintenso catolicismo. Isso resultou, entre outras coisas, em forte censura a condutas dissidentes moralmente, entre elas o homossexualismo. Daí que, aos moços da Irlanda do Sul, elementos que permitissem construir uma eventual identidade homossexual eram simplesmente barrados. Não havia possibilidade de compreenderem, eles, suas pulsões dedesejo voltadas para o mesmo sexo como significando um desejo, não digo sequer tolerável: a repressão era tão forte que negava a esse amor o próprio reconhecimento. A conclusão foi queo nomedisponível para esseconjunto de desejos dissidente não era o homossexualismo, mas a vocação sacerdotal. O menino que não desejava meninas não entendia essenão-desejo como um desejo por homens, mas como a vocação de servir a Deus.

Osresultados desseaprisionamento dalibido foram trágicos. Umnúmero quenão podemos saber de padres sofreu, profundamente, de não ter satisfeito a sua sexualidade. Não poucos sacerdotes católicos, tendo por única saída a satisfação de sua homossexualidade no ambiente masculino do clero, e não dispondo de facilidades de intercurso com outros adultos, reciclaram-se na pedofilia.

O irônico efeito disso, no que tange à instituição responsável por esse processo, é quehojeaimagem da I greja Católicana Irlanda se ressente de fortes acusações no que se refere a processos de corrupção de menores, por um lado, e a procedimentos para abafar escândalos e destruir vidas individuais, por outro.

Dessetristeepisódio, o quepodemos retirar é que um maior acesso a elementos de cultura 1 - nocaso, obras literáriaseartísticasexpondo a homossexualidade - teria aberto mais os corações ementestanto dosjovensirlandeses de tendência homossexual quanto de seus compatriotas, que teriam visto a sociedadee a condição humana como mais complexas, e por conseguintemais ricas do quepensaram.

Ou seja, que o modo pelo qual tantos jovens foram-se tornando humanos - o trabalho da cultura-2 - teria sido bem mais rico se fosse maior o seu acesso à cultura-1.

Emsuma, sequeremosentender aculturaem nova chave, sea desejamos compreender em seu estratégico papel social, a articulação dos 
dois usos do termo é fundamental, e ela implica essa mudança de enfoque, na qual consideramos os indivíduos que têm contato comasbelas-artes, como patrimônio cultural, com o mel hor quea humanidadefoi capaz de criar (vê-sequeadoto aqui ostermoscorrentes para a cultura-1), não mais como receptores mais ou menos passivos deconteúdos dados, mas como aqueles que fazem intenso uso dessarelação comacultura para constituírem sua frágil humanidade.

\section{Notas}

1 Cf., a propósito de conceitos aparentados - história, soberania e revolução - o penúltimo ensaio de meu Última razão dos reis: ensaios de filosofia e de política, São Paulo, Companhia das Letras, 1993.

2 A idéia de um modelo "Europa do Norte" é de Quentin Skinner, em suas Fundações do pensamento político moderno, São Paulo, 1995.

3 São Paulo, ed. Brasiliense, 1977.

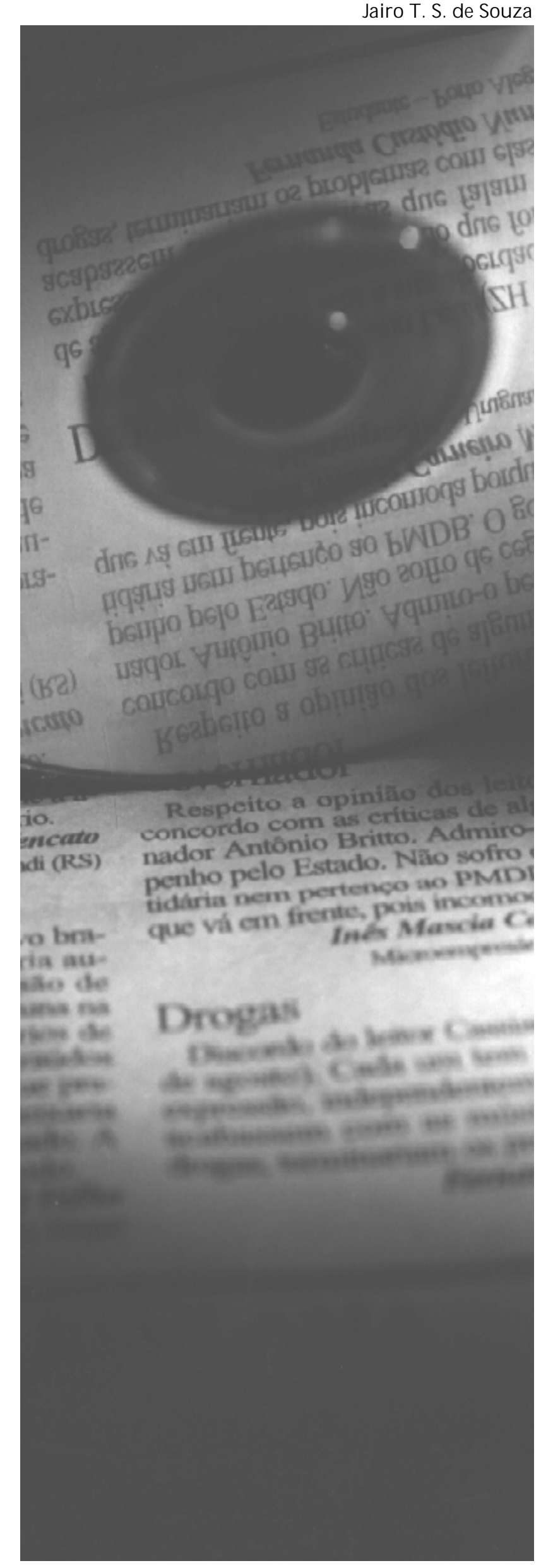

